\title{
Simulation and Experimental Study on the Steady Conduction Solution for Continuous Rheo-Casting for A356 Alloy
}

\author{
Do Minh Duc, Nguyen Hong Hai, and Pham Quang* \\ Key Laboratory of Metal Materials Technology, Hanoi University of Science and Technology (HUST), No.1 Dai Co Viet, \\ Hanoi, Vietnam
}

\begin{abstract}
Computational fluid dynamic modeling of a continuous rheo-casting technology was conducted, consistent with the manufacturing of $3 \mathrm{~mm}$-thin plates made of aluminum alloy A356. The A numerical simulation on of the stabilizing time of the material crystallization was carried out using the ANSYS FLUENT code. Solidification and melting models were simulated with heat transfer and solid-liquid phase transformation involving the latent heat of crystallization were simulated. The calculated temperature distribution and the evolution of cooling rate through the material were examined and used to clarify their influence on microstructure, and further investigated with hardness testing. The thickness of the mushy zone was determined for the steady conduction solution of the continuous rheo-casting process.
\end{abstract}

(Received December 29, 2015; Accepted August 9, 2016)

Keywords: semisolid processing, solidification, solid - liquid phase transition, computer simulation

\section{INTRODUCTION}

Semi-solid metal (SSM) processing has emerged as an attractive method for near-net-shape manufacturing due to its distinct advantages over conventional near-net-shape forming technologies. These advantages include lower cycle time, increased die life, reduced porosity, limited solidification shrinkage, improved mechanical properties, etc. The SSM processing techniques not only allow the production not only of complex dimensional details (e.g., thin-walled sections) usually associated with conventional high-pressure die castings, but also of high integrity castings that are currently attainable only with squeeze and low-pressure permanent mold casting. There are two primary semi-solid processing routes: thixocasting and rheocasting.

Continuing efforts to reduce processing costs have led to the development of several rheocasting (also termed slurry-on-demand) processes. These include UBE's New Rheocasting (NRC) [1], Idra-Prince's Semi-Solid Rheocasting (SSR) [2], THT Presses' Sub-Liquidus Casting ( $\mathrm{SLC}^{\mathrm{TM}}$ ) [3], and Alcan's Swirl Enthalpy Equilibration Device (SEED) [4], as well as the Continuous Rheoconversion Process $\left(\mathrm{CRP}^{\mathrm{TM}}\right)$ [5], developed by ACRC/MPI. In the $\mathrm{CRP}^{\mathrm{TM}}$ is a process, where the molten metal flows through a reactor prior to casting. The role of the reactor is to ensure that a extensive nucleation takes place and that the nuclei are well distributed throughout the system, prior to entering the casting cavity. The CRP ${ }^{\mathrm{TM}}$ has been successfully applied in to hyper-eutectic Al-Si alloys (i.e. 390 alloy) where two liquids of equal or different compositions and temperatures are mixed in the reactor and create a SSM slurry.

In 1967, Mizikar [6] introduced an approach that about involved the effect of convection currents in the heat transfer model, and a heat transfer method known as effective thermal conductivity. In this method, instead of calculating fluid flow by with the Navier-Stokes equation, an increase the in heat transfer fluid is associated with the changing thermal conductivity of the steels. The thermal conductivity between the liquid metal and the mushy zone is raised by a quantity $A$, and the heat transfer process does not occur when the A value is 1 . This method of thermal conductivity is described with Equation $1[7,8]$,

$$
k_{e f f}=k f_{s}+A k\left(1-f_{s}\right)
$$


where $k_{e f f}$ is the effective thermal conductivity, $\mathrm{k}$ is thermal conductivity, $f_{s}$ is the solid fraction and $A$ is a parameter ranging from 1 to 12 .

Although this method has been widely used in the heat transfer model [6,7,9-12] for the continuous casting of steels, but a few researchers $[7,9,10,12]$ have questioned about its accuracy. The parameter A is often arbitrary and chosen to match with experiments. Karlinski et al. [7] studied the influence of parameter A (1.5-5) in the solid-liquid transition. They found that A has only a minor influence on solidus temperature but a much more profound effect on the liquidus isotherm. Mizikar [6] and Lait et al. [9] used $A=7$ for their studies. They found that there was only a slight difference for solid shell thickness, although their research was limited to only just to the mould area.

To use [6] Mizikar's method of effective thermal conductivity, Szekely and Stanek [10] studied the impact of flow pattern in a liquid metal container by producing a flow pattern on an outer liquid metal. They found that the solidus is not affected by the flow pattern, but the superheat removal rate is markedly affected. Choudhary et al. [12] investigated the heat transfer in the continuous casting process of a low carbon cast billet and compared two approaches about to effective thermal conductivity: where thermal conductivity efficiency extends to the mushy zone as a function of the fluid, and where there is no thermal effect, resulting in the mushy zone. The temperature differences were clearly shown expressed in shell thickness and billet midface.

In the early days of SSM and CRP developments [13-17], it was thought that one had to cool the liquid down into the two-phase region, and to shear off and break the dendrites (i.e., melt agitation via mechanical or, later on, magnetohydrodynamic -(MHD) stirring) and thus producing a slurry. In more recent years, the projects sponsored by the National Research Program KC02-23/06-10 and by the Department of Science and Technology of Hanoi City, were carried out by the research team of the Key Laboratory of Metal Materials Technology to produce a semi-solid structure of the globular primary alpha phase via continuous rheo-casting and rheo-die casting [18-23]. From these studies it was found, that if the melt temperature was chosen so that many nuclei could be produced ("extensive nucleation"), and if they did not melt back into the bulk liquid, then a slurry with the ideal semi-solid structure could be produced directly from the melt.

\section{METHODLOGY}

\subsection{Computational Fluid Dynamics}

Computational fluid dynamics [24] is method for simulating fluid flow, heat and mass transfer and phenomena related to solving mathematical equations numerically. The elements in the melt bulk are simulated via flow rate $u$, pressure $\rho$, specific weight $\rho$ and energy $E$, and are summerized in the fuild flow equation [24]:

$$
\underbrace{\frac{\partial}{\partial t} \int_{V} \rho \phi d V}_{\text {unsteady }}+\underbrace{\oint_{A} \rho \phi V d A}_{\text {onvection }}=\underbrace{\oint_{\text {generation }} S_{\phi} d V,}_{\underbrace{A}_{\text {diffusion }} \Gamma \nabla \phi d A}
$$

where $\phi$ is the density of the diffusing material (continuity $=1 ; x$-momentum $=u ; y$-momentum $=v$ and energy $=h), \mathrm{V}$ is the volume of the control volume element, $A$ is the surface area of the control volume element, and $\Gamma$ is the collective diffusion coefficient for density.

\subsection{Solidification model}

This model is applied to simulate processes involving heat transfer and solid-liquid-vapor transformations, used in the FLUENT software. In this software the target function is enthalpy. The enthalpy $H$ of a system can be calculated as a the sum of apparent $h$, and latent heats $\Delta H$; with $h_{r e f}$ as the reference enthalpy, $T_{r e f}$ as the reference temperature and $c_{p}$ as the isobaric specific heat [25]:

$$
\begin{aligned}
& H=h+\Delta H \\
& h=h_{r e f}+\int_{T_{r e f}}^{T} c_{p} d T .
\end{aligned}
$$

The liquid fraction can be determined as [16]: 


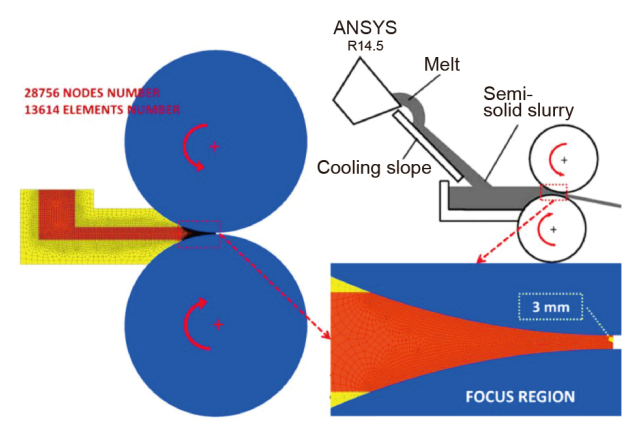

Fig. 1. The numerical geometry and the predefined section in cooling channel

$$
\begin{aligned}
& \beta=0 \text { if } T<T_{\text {solidus }} \text { and } \beta=1 \text { if } T>T_{\text {liquidus }} . \\
& \beta=\frac{T-T_{\text {solidus }}}{T_{\text {liquidus }}-T_{\text {solidus }}}, \text { with } T_{\text {solidus }}<T<T_{\text {liquidus }} .
\end{aligned}
$$

The latent heat $\Delta H$ can be found as: $\Delta H=\beta L$,

where $L$ is the latent heat during the crystallization process of metals and alloys. The value of latent heat can vary from 0 (for solid) to $L$ (for liquid). In the case of the solidification of a multicomponent alloys, the theoretical liquidus temperature can be calculated as follows [25]:

$$
T_{\text {liquidus }}=T_{\text {melt }}+\sum_{\text {solutes }} m_{i} Y_{i}
$$

where: $Y_{i}$ is the weight fraction of the $i$-solute; $m_{i}$ - is the curvature for $Y_{i}$. For solidification problems, the governing energetic equation can be written in the form:

$$
\frac{\partial}{\partial t}(\rho H)+\nabla \cdot(\rho \cdot \bar{v} H)=\nabla \cdot\left(K_{i} \nabla T\right)+S,
$$

where $\rho$ is the specific weight; $\vec{v}$ - is liquid velocity; $K_{i}$ is the distribution coefficient at the solid/liquid interface, and $S$ - is the internal source of heat. The solution for the temperature field is the an irrelative solution of the flow equations (2) - (4), governing the energetic equation (9) and equation for the liquid fraction (7).

\subsection{Modelling and Nummerical Simulation}

One of the key points of interest in the continuous rheo-casting process is the mushy zone, which is the area where liquid and solid exist simultaneously, and until before the final solidification when and the strand cannot be cut to the final dimensions. The mushy zone and its position are also important for the microstructure and defect formation. The solidification process begins when the liquid metal is exposed to the cooled roller, and it depends on employing the appropriate time and casting speed.

The simulation in this study was conducted to solve the stability problem (proper appropriate time). The numerical simulation of to determine the stabilizing time of the alloy crystallization was carried out by used ANSYS FLUENT (ANSYS Workbench - Fluid Flow (FLUENT)) code [26], assuming that the metal was poured from a graphite container down into a cooling slope and then to cooling rollers.

Figure. 1 shows the numerical geometry and the pre-defined section in the cooling zone. A melt drag twin roll caster (MDTRC) was used [27], in view of its suitability for the high-speed roll casting of aluminum alloy. Two steel rollers were employed, whose rolling speed enables a change of in cooling rate. A lubricant is conventionally used in present studies in order to prevent the strip from sticking to the roll. However, spraying lubricant on the roller surface may affect heat transfer between the rollers and the metal, and this was taken into account during the simulation process. The temperature of the cooling roller, and the temperature variation and solidification rate of the metal are parameters to be determined for in the process of heat exchange between the liquid metal and the static cooling roller.

The developed model was used to simulate the cooling process. Starting with an existing 2D mesh, the details regarding of the setup and the solution procedure for the solidification problem were input. The steady conduction solution for this problem is was computed and served after as an initial condition for the next problem. The simulation model also included the a container made of graphite for holding the liquid metal container made of graphite.

The initial temperatures of the container, roller, liquid A356 alloy and environment were 753, 397, 903 and $303 \mathrm{~K}$ respectively. Data for the thermal-physical properties are presented in Table 1 [28]. The contact resistance (Rc) 
Table 1. Thermal-physical properties of A356 alloy, roller and container materials

\begin{tabular}{|c|c|c|c|c|}
\hline \multirow{2}{*}{ Thermal-physical properties } & \multirow{2}{*}{ Container, graphite } & \multirow{2}{*}{ Roller, C45 } & \multicolumn{2}{|c|}{ A356 } \\
\hline & & & Solid & Liquid \\
\hline Temperature [K] & & & 828 & 888 \\
\hline Bulk density $\left[\mathrm{kg} \cdot \mathrm{m}^{-3}\right]$ & 1950 & 7500 & 2700 & 2380 \\
\hline Specific heat capacity $\left[\mathrm{J} \cdot \mathrm{kg}^{-1} \cdot \mathrm{K}^{-1}\right]$ & 750 & 690 & 900 & 1200 \\
\hline Thermal conductivity $\left[\mathrm{W} \cdot \mathrm{m}^{-1} \cdot \mathrm{K}^{-1}\right]$ & 250 & 35 & 126 & 94 \\
\hline Latent heat $\left[\mathrm{J}^{\mathrm{kg}} \mathrm{kg}^{-1}\right]$ & & & \multicolumn{2}{|c|}{389000} \\
\hline Viscosity $\left[\mathrm{kg} \cdot \mathrm{m}^{-1} \cdot \mathrm{s}^{-1}\right]$ & & & \multicolumn{2}{|c|}{$0.15(873 \mathrm{~K})$} \\
\hline Heat transfer coef.: casting -container $\left[\mathrm{W} \cdot \mathrm{m}^{-2} \cdot \mathrm{K}^{-1}\right]$ & 2000 & & & \\
\hline Contact resistance: casting-container $\left[\mathrm{m}^{2} .-\mathrm{K} \mathrm{W}^{-1}\right]$ & 5 & & & \\
\hline Heat transfer coef.: casting-roller $\left[\mathrm{W} \cdot \mathrm{m}^{-2} \cdot \mathrm{K}^{-1}\right]$ & & 2000 & & \\
\hline Contact resistance: casting-roller $\left[\mathrm{m}^{2} .-\mathrm{K} . \mathrm{W}^{-1}\right]$ & & 5 & & \\
\hline Heat transfer coef.: container-environment $\left[\mathrm{W} \cdot \mathrm{m}^{-2} \cdot \mathrm{K}^{-1}\right]$ & 100 & & & \\
\hline Heat transfer coef.: roller-environment $\left[\mathrm{W} . \mathrm{m}^{-2} \cdot \mathrm{K}^{-1}\right]$ & & 50 & & \\
\hline
\end{tabular}

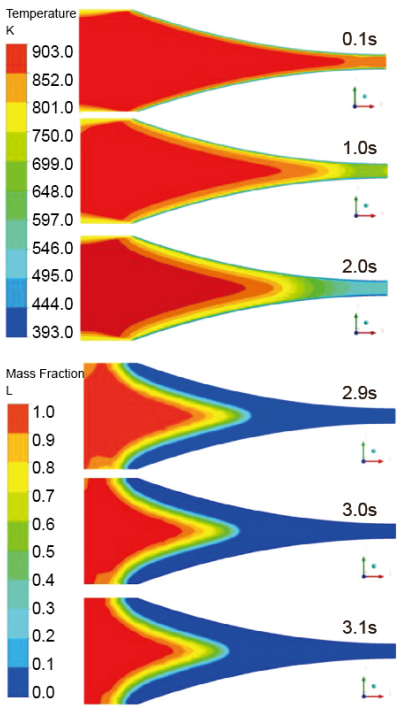

(a)
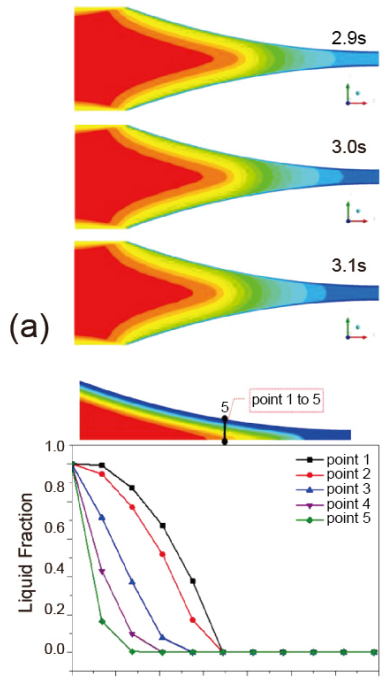

(b)

Fig. 2. Simulation results of (a) temperature field and (b) mass (liquid) fraction

between the melt with the container and between the melt with the roller were determined through by experiment.

\subsection{Microstructure Characterisation and Hardness Testing}

To establish determine any relationship between the microstructural features and properties of the alloy, samples were cut from identical test positions. After polishing and etching with $10 \% \mathrm{NaOH}$, a Zeiss Axiovert 25 microscope was used to observe the microstructure and determine grain size. The as-cast samples were kept at room temperature for some weeks before conducting hardness measurements using a Vickers tester with a load of $0.1 \mathrm{~kg}$. The Vickers hardness values were the average of at least five indentations.

\section{RESULTS AND DISCUSSION}

As shown in Figures. 2a, at 0.1, 1, 2, 2.9, 3.0 and 3.1 s, the temperature contours are fairly uniform through the melt front and solid material. In the continuous rheo-casting process, it is important to pull out the solidified metal at the proper time. If the metal is pulled out too early, it may still be in a mushy state. If it is pulled out too late, it could solidify in the casting pool and cannot be pulled out as a whole. An optimal pulling rate can be determined from the profile for liquidus and solidus temperatures.

The entering rate of entry of the liquid metal at from the left of the heat exchange domain must be balanced with the rate of pulling rate of the solidified metal from the right and this can be ensured by appropriate pulling rate. After 3 seconds, the equilibrium position of the melt front is well established, as shown in Figs. 2 b.

The melt stream, characterized by the liquid fraction, becomes more narrow from the beginning to the end of the cooling channel. However, the solid stream, identified by the solid fraction and grain size, is behaves the opposite. As 


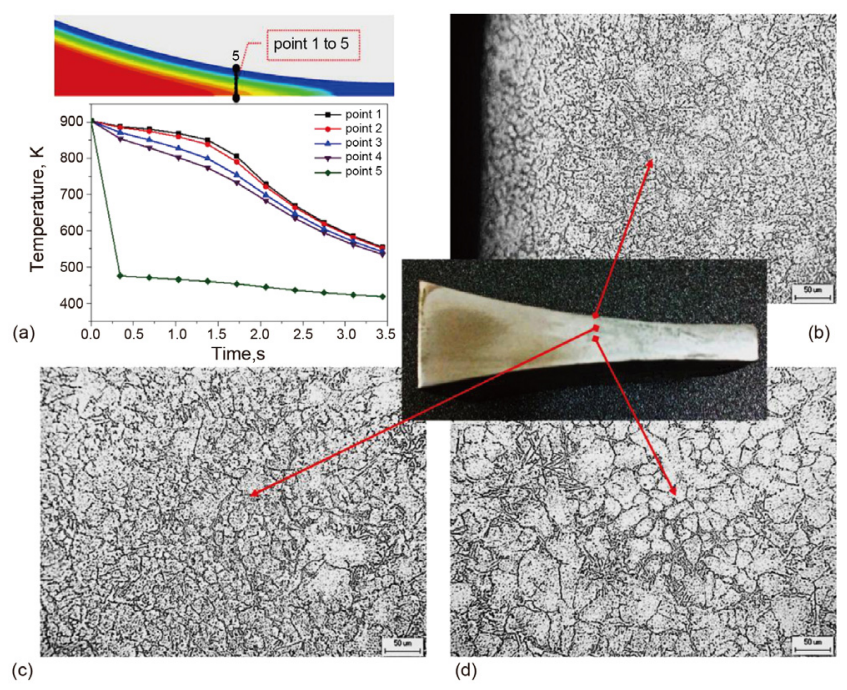

Fig. 3. (a) Cooling curve in cross section (points 1 to 5) and optical micrographs of samples at (b) the contact surface, (c) the middle and (d) the center of casting

discussed above, nucleation occurs in the input position by due to sudden chilling and then the nuclei are pushed by the melt towards the end of the cooling channel, and grow to grains afterwards.

Figure. 3a represents the temperature profile resulted measured at the points 1, 2, 3, 4 and 5 in the cooling channel. The largest cooling rate, of about $1050 \mathrm{~K} / \mathrm{s}$, was reached at the contact surface between the casting and roller (point 5) about $1050 \mathrm{~K} / \mathrm{s}$; for the other positions $1,2,3$ and 4, the cooling is slower, with a reduced cooling rate in the range of $(110 \div$ to 115$) \mathrm{K} / \mathrm{s}$.

In the stability studies involving, steady conduction state, the a crystallization process commonly occurs immediately as the liquid metal is poured into the container because the heat exchange immediately begins between the metal and the container. The liquid metal temperature comes down gradually to the solidification temperature and crystallization occurs from the contact surfaces with the cooling roller toward the casting center.

Microstructures of the casting from the periphery to its center (point 5 to point 1 ) are shown in Fig. 3. The grain size at the contact surface (point 5 ) is finer than that at the casting center (point 1), but several traces of dendrites are still visible on the surface (Fig. 3b). The best globular grains are present in the middle (points 2-4, Fig. 3c). In the casting center the

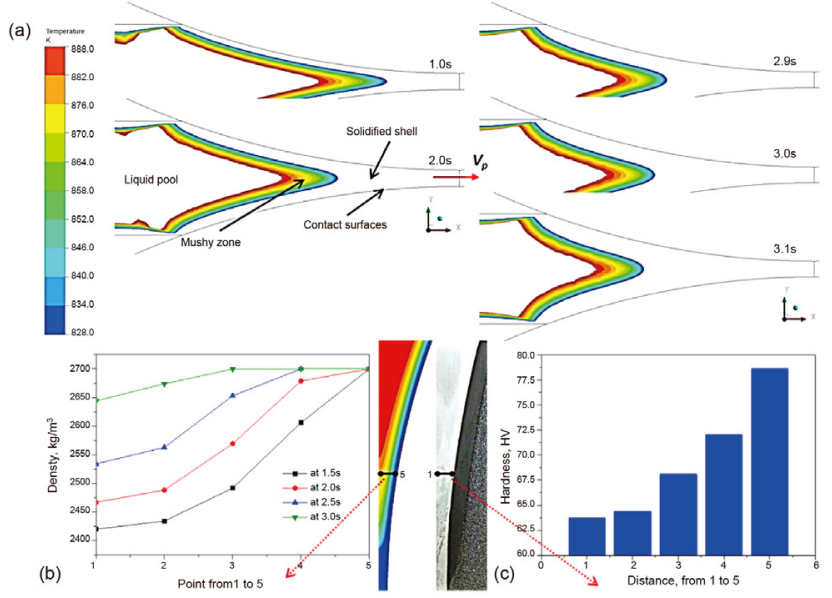

Fig. 4. Display of temperature contours to determine thickness of mushy zone (a),

profile of density (b) and corresponding hardness values (c)

grains became rounder but coarse (Fig. 3d).

This difference in microstructures is explained by the change of in cooling rate from between the surface area in contact with the cooling roller and the casting center. Because the solidification proceeds from the contact surface to the casting center, the cooling rate of the first must be always higher than that of the second. Moreover, a dendrite fragmentation is expected to take place, creating the ideal nuclei and leading to the globular microstructures, which are well developed at in the middle section, as shown in Fig. 3c.

In the continuous rheo-casting process, the solidified metal is continuously pulled out from the solidified domain. The liquid pool, the mushy zone and the solidified shell are shown in Figure. 4 (a). Consequently, the solid metal will have a finite velocity that which needs to be considered taken into account by in the enthalpy-porosity technique.

As mentioned, the enthalpy-porosity approach treats the solid-liquid mushy zone as a porous medium with the a porosity that is equal to the liquid fraction. A suitable sink term is added in the momentum equation to consider reflect the pressure drop due to the porous structure of the mushy zone. For continuous rheo-casting applications, the relative velocity between the molten liquid and the solid is used in the momentum sink term, rather than the absolute velocity of the liquid.

The mushy zone constant $A_{\text {mush }}$ measures the amplitude of 
the damping; the higher this value, the steeper the transition of the metal velocity to zero as it solidifies. Very large $A_{m u s h}$ values may cause the liquid metal to oscillate. The pull velocity is included to the account for the movement of the solidified metal as it is continuously withdrawn in the continuous rheo-casting process. The presence of this term in the equation allows the newly solidified metal to move with the pull velocity. The momentum sink due to the reduced porosity in the mushy zone takes the following form [25]:

$$
S=\frac{(1-\beta)^{2}}{\left(\beta^{3}+\epsilon\right)} A_{m u s h}\left(\vec{v}-\vec{v}_{p}\right),
$$

where $\epsilon$ is a small number (0.001) to prevent division by zero; $A_{\text {mush }}$ is the mushy zone constant, and $\vec{v}_{p}$ is the solid velocity which corresponds to the pulling of the solidified material out of the solidified domain (also referred to as the pull velocity).

An exact calculation of the pull velocity for of the solid metal is dependent on the Young's modulus and Poisson's ratio of the solid and the forces acting on it. ANSYS FLUENT uses a Laplacian equation to approximate the pull velocities in the solid region based on velocities at the boundaries of the solidified region [25]:

$$
\nabla^{2} \vec{v}_{p}=0
$$

The density profiles corresponding in to different times (at 1.5, 2.0, 2.5 and $3 \mathrm{~s}$ ) are shown in Fig. 4b. It is noted that the density increased from the point 1 to the point 5 . The distribution of hardness test shown in Fig. $4 \mathrm{c}$ is in good agreement with that of density. The measured hardness values are $79 \mathrm{HV}$ at the contact surface (point 5) and $64 \mathrm{HV}$ in the casting center (point 1). Obviously, grain size plays a dominant role in this finding. The difference in grain size depends on the cooling rate mentioned above (Fig. 2b) from point 1 to point 5, i.e., from the casting center to the contact surface with of the cooling roller. This difference is mainly caused by the evolution of heat and temperature.

A heat transfer model with including contact resistance between the liquid metal and the cooling roller was simulated and was proved perfectly in this study.

This research approach and results shed light on various advanced casting processes [29, 30] and modeling [31-34].

\section{CONCLUSIONS}

The ANSYS FLUENT code uses the following boundary conditions for computing the steady conduction solution: the liquid-solid interface, the heat transfer with including contact resistance between the liquid metal and the cooling roller and at a zero-gradient velocity. The solidification model was used successfully for modeling the continuous rheo-casting processes, where the solid metal is continuously pulled out from the casting domain.

The steady conduction solution was simulated and verified using experiments. The following results were obtained:

(1) The temperature field, mass (liquid) fraction and temperature profile were simulated; the cooling rates at the casting surface were calculated to be about $1050 \mathrm{~K} / \mathrm{s}$, and inside the casting - to be about $(110 \div 115) \mathrm{K} / \mathrm{s}$; their correlation with the microstructures was clarified.

(2) The temperature profile was displayed to determine the thickness of the mushy zone, which formed during the time interval from 0 to $3.5 \mathrm{~s}$; the metal density changed correspondingly from $2425 \mathrm{~kg} / \mathrm{cm}^{3}$ at the center to 2650 at the contact surface. The results of the hardness test were in the full agreement with those for density.

(3) Using the constant value $A_{\text {mush }}$ (for 2.9 - $3.1 \mathrm{~s}$ ) approach and an unchanging pull velocity unchanged over the casting domain, seems to be less expensive than using ANSYS FLUENT to calculate the pull velocities.

\section{ACKNOWLEDGEMENT}

This study was carried out at Key laboratory of Metal Materials Technology, the Hanoi University of Science and Technology under sponsorship of Materials research program, Department of Science and Technology of the Hanoi city. 


\section{REFERENCES}

1. UBE Industries Ltd., in European Patent, EP 0745694 A1, 117 (1996).

2. J. A. Yurko, R. A. Martinez, and M. C. Flemings, 8th International Conference on Semi-Solid Processing of Alloys and Composites (eds. A. Alexandrou, G. Georgiou, M. Makhlouf and D. Apelian), Limassol, Cyprus, JLJ Technologies and WPI MPI, USA (2004).

3. J. L. Jorstad, 8th International Conference on SemiSolid Processing of Alloys and Composities, (eds. A. Alexandrou, G. Georgiou, M. Makhlouf and D. Apelian), Limassol, Cyprus, JLJ Technologies and WPI MPI, USA (2004).

4. D. Doutre, J. Langlais, and S. Roy, 8th International Conference on Semi-Solid Processing of Alloys and Composites, (eds. A. Alexandrou, G. Georgiou, M. Makhlouf and D. Apelian), Limassol, Cyprus, JLJ Technologies and WPI MPI, USA (2004).

5. Q. Y. Pan, M. Findon, and D. Apelian, 8th International Conference on Semi-Solid Processing of Alloys and Composites, (eds. A. Alexandrou, G. Georgiou, M. Makhlouf and D. Apelian), Limassol, Cyprus, JLJ Technologies and WPI MPI, USA (2004).

6. E. A. Mizikar, Trans. Met. Society AIME 239, 1747 (1967).

7. V. Karlinski, S. Louhenkilpi, and J. A. Spim, Mathematical Formulas, Parameter Study and Effect of Steel Grade 40th Steelmaking Seminar International, Brazil (2009).

8. S. Louhenkilpi, Mater. Sci. Forum 414-415, 445 (2003).

9. J. E. Lait, J. K. Brimacombe and F. Weinberg, Ironmaking \& Steelmaking 2, 90 (1974).

10. J. Szekely and V. Stanek, Met. Trans. 1, 119 (1970).

11. S. K. Choudhary, D. Mazumdar, and A. Ghosh, ISIJ International 33, 764 (1993).

12. E. Y. Ko, J. Choi, J. Y. Park, and I. Sohn, Met. Mater. Int. 20, 141 (2014).

13. J. J. Park, Met. Mater. Int. 20, 317 (2014).

14. J. H. Cho, H. W. Kim, C. Y. Lim, and S. B. Kang, Met. Mater. Int. 20, 647 (2014).

15. G. Timelli, G. Camicia, S. Ferraro, and R. Molina, Met. Mater. Int. 20, 677 (2014).

16. F. H. Yekta and S. A. Sadough Vanini, Met. Mater. Int.
21, 913 (2015)

17. N. H. Hai, D. M. Duc, N. N. Tien, and N. T. Tai, $A d v$. Tech. Mater. Produ. Proc., (eds. V. Y. Shchukin, G. V. Kozhevnikova and K. D. Kirdun), Belarus National Academy of Sciences, 209 (2011).

18. P. Quang, N. H. Hai, and D. M. Nghiep, Adv. Tech. Mater. Produ. Proc., (eds. V. Y. Shchukin, G. V. Kozhevnikova and K. D. Kirdun) Belarus National Academy of Sciences, 225 (2011).

19. D. M. Duc, N. H. Hai, and P. Quang, Sci. Tech. Metals 46, 37 (2013).

20. N. T. Tai, D. M. Duc, N. H. Hai, and P. Quang, J. Sci. Tech. 5A, 201 (2013).

21. N. T. Tai, D. M. Duc, N. H. Hai, and P. Quang, J. Sci. Tech. 5A, 194 (2013).

22. D. M. Duc, N. T. Tai, N. H. Hai, and P. Quang, Proc. of the 15th International symposium on Eco-materials processing and design (ISEPD2014) (eds. B. T. Long, B. V. Ga and K. Niihata) 404 (2014).

23. J. Blazek, "Computational Fluid Dynamics: Principles and applications", Elsevier Science Ltd., Oxford, UK (2001).

24. ANSYS FLUENT 14.1, "Theory guide", Ch. 1. Basic fluid flow, ANSYS, Inc. (2011).

25. ANSYS FLUENT 14.1, "Theory guide", Ch. 17. Solidification and melting, ANSYS, Inc. (2011)

26. ANSYS FLUENT 14.1 Software, ANSYS, Inc. (2011)

27. T. Haga, J. Mater. Pro. Tech. 130-131, 558 (2002).

28. E. A. Brandes, "Smithells Metals Reference Book" (Seventh Edition) Published by Butterworth \& Co. Ltd (1983).

29. M. Azizieh, R. Bahadori, M. Abbasi, E. Y. Yoon and H. S. Kim, Inter. J. Cast Metals Research 28, 345 (2015).

30. J. H. Lee, H. S. Kim, B. Cantor and C. W. Won, Mater. Sci. Eng. 338A, 182 (2002).

31. H. S. Kim, Mater. Trans. 42, 536 (2001).

32. H. S. Kim, Y. S. Lee, S. I. Hong, A. A. Tarakanova, and I. V. Alexandrov, J. Mater. Proc. Technol. 142, 334 (2003).

33. P. Quang, Y. G. Jeong, S. C. Yoon, S. H. Hong, and H. S. Kim, J. Mater. Proc. Tech. 187-188, 318 (2007).

34. S. C. Yoon, A. V. Nagasekhar, J. H. Yoo, M. I. A. E. Aal, M. Vaseghi, and H. S. Kim, Mater. Trans. 51, 46 (2010). 